\title{
Central Obesity, Leptin and Cognitive Decline: The Sacramento Area Latino Study on Aging
}

\author{
Adina Zeki Al Hazzouria,b Mary N. Haan ${ }^{\mathrm{a}}$ Rachel A. Whitmer ${ }^{c}$ Kristine Yaffe ${ }^{\mathrm{a}, \mathrm{b}}$ \\ John Neuhaus ${ }^{\mathrm{a}}$ \\ Departments of a Epidemiology and Biostatistics and besychiatry, School of Medicine, University of California \\ San Francisco, San Francisco, Calif., and 'Kaiser Permanente, Northern California Division of Research, Oakland, \\ Calif., USA
}

\section{Key Words}

Aging • Cognition • Obesity • Leptin • Longitudinal study • Mexican Americans

\begin{abstract}
Background/Aims: Central obesity is a risk factor for cognitive decline. Leptin is secreted by adipose tissue and has been associated with better cognitive function. Aging Mexican Americans have higher levels of obesity than nonHispanic Whites, but no investigations examined the relationship between leptin and cognitive decline among them or the role of central obesity in this association. Methods: We analyzed 1,480 dementia-free older Mexican Americans who were followed over 10 years. Cognitive function was assessed every 12-15 months with the Modified Mini Mental State Exam (3MSE) and the Spanish and English Verbal Learning Test (SEVLT). Results: For females with a small waist circumference ( $\leq 35$ inches), an interquartile range difference in leptin was associated with $35 \%$ less 3 MSE errors and $22 \%$ less decline in the SEVLT score over 10 years. For males with a small waist circumference ( $\leq 40$ inches), an interquartile range difference in leptin was associated with $44 \%$ less 3 MSE errors and $30 \%$ less decline in the SEVLT score over 10 years. There was no association between leptin and cognitive decline among females or males with a large waist circumference. Conclusion: Leptin interacts with central obesity in shaping cognitive decline. Our findings provide
\end{abstract}

\section{KARGER \\ Fax +41613061234 \\ E-Mail karger@karger.ch}

www.karger.com
(C) 2012 S. Karger AG, Basel

$1420-8008 / 12 / 0336-0400 \$ 38.00 / 0$

Accessible online at:

www.karger.com/dem valuable information about the effects of metabolic risk factors on cognitive function.

Copyright @ 2012 S. Karger AG, Basel

\section{Introduction}

Cognitive impairment and dementia constitute major public health concerns $[1,2]$. Total body and central obesity, particularly in midlife, have been associated with worse cognitive impairment and dementia [3-6] through several potential mechanisms including insulin resistance [7-9] and type 2 diabetes [10-13]. Adipose tissue is a primary source for the production and secretion of leptin making it a biomarker of body fat [14]. A growing body of evidence suggests that leptin is associated with lower rates of cognitive decline and dementia. Possible mechanisms by which leptin may influence cognition include modulation of synaptic plasticity [15-17] and clearance of $\beta$-amyloid [18]. Importantly, obese people are likely to develop leptin resistance $[19,20]$. Leptin resistance may attenuate the beneficial action of leptin on the brain $[19,21-23]$ and may be responsible for the lack of protective effect of leptin on dementia and Alzheimer's disease (AD) among obese people [24, 25]. Among nonobese people, leptin resistance is less likely to develop and thus leptin may exert its protective effect. 
Despite the apparently complex associations of leptin, obesity, and cognitive function, the majority of work has been limited to rodent models $[26,27]$ with only a handful of population-based studies in humans $[24,28,29]$. Furthermore, these associations remain relatively unexplored among racial or ethnic groups such as Mexican Americans. Mexican Americans and some other minority groups are disproportionately burdened with general and central obesity [30] and type 2 diabetes [10-13], as compared to non-Hispanic whites [7]. In light of possible racial/ethnic differences in metabolic risk profiles $[10-13,30]$ as well as leptin concentrations [31-34], the association of leptin, obesity, and cognitive function may be different for Mexican Americans compared to other racial or ethnic groups.

We sought to evaluate the relationship between leptin, central obesity, and cognitive decline over 10 years in a prospectively followed cohort of older Mexican Americans. We hypothesized that higher leptin would be associated with slower rates of cognitive decline and that such associations would be more statistically significant for participants with low central obesity and not for those with high central obesity, possibly due to leptin resistance.

\section{Materials and Methods}

\section{Study Population}

Participants in this study were from the Sacramento Area Latino Study on Aging (SALSA). SALSA is a prospective cohort study of 1,789 community-dwelling older Mexican Americans aged 60-101 years at baseline in 1998-1999. Every 12-15 months, biological and clinical data were collected on participants in home visits for a maximal total of 6 follow-ups. Of the total sample, about $49 \%$ were born in the USA and 51\% were born either in Mexico (45\%) or other Latin American country (6\%). SALSA has been approved by the institutional review board at the University of Michigan and the University of California, Davis. Further details on the study design and recruitment strategy have been published elsewhere [35].

A total of 1,595 participants had their serum leptin level measured at baseline. Compared to participants with leptin measurement, those without leptin measurement $(\mathrm{n}=194)$ were older, more likely to be Mexican-born, had lower education and lower income, were less likely to have hypertension, and had lower mean cognitive scores. Of the 1,595 participants, 108 had a dementia diagnosis at baseline and 7 had missing gender information and were excluded. A total of 1,480 constituted the final sample size for this analysis. Those 1,480 participants were followed in the field for an average of 6.2 years $(\mathrm{SD}=2.7)$. Mortality surveillance is still ongoing.
Measures

Cognitive Function. For all participants, cognitive function was assessed using two cognitive tests, namely the Modified Mini Mental State Exam (3MSE) and the Spanish English Verbal Learning Test (SEVLT). The 3MSE is a 100-point global cognitive test ranging from 0 to 100 . The 3MSE was validated and field-tested in both English and Spanish. Compared to the Mini Mental State Exam, the 3MSE shows better reliability, test-retest properties, better sensitivity and specificity and fewer ceiling effects $[36,37]$. We examined the number of errors on the 3MSE (calculated as 101 - 3MSE score) which was then log transformed to closely correspond to a normal distribution. Higher scores on log (3MSE errors) denote worse cognitive function. The SEVLT is a verbal memory recall test with four 15-word memory trials, an interference list, followed by a fifth trial which is usually used as the test score $[38,39]$. The SEVLT was developed for use in the SALSA [39]; it has been validated in both English and Spanish and has been used in other studies. The SEVLT test scores range from 0 to 15 with higher scores denoting better cognitive function.

Leptin. At baseline, leptin was measured from fasting blood drawn using standard venipuncture into evacuated tubes. Serum leptin assays were done using the leptin radioimmunoassay kits from Linco Research Inc. (St. Charles, Mo., USA). Purified recombinant human leptin was used as standard. Limit of sensitivity for the assay was $0.5 \mathrm{ng} / \mathrm{ml}$. Interassay coefficient of variation was $4.6 \%$ at $3.0 \mathrm{ng} / \mathrm{ml}$ and $2.0 \%$ at $20.0 \mathrm{ng} / \mathrm{ml}$.

Anthropometric and Obesity Measures. At baseline, standing height was measured using a portable stadiometer; weight was determined using a standard scale. Body mass index (BMI) was then calculated as weight (in kilograms) divided by the square of height (in meters) and classified as normal $(<25.0)$, overweight (25.0-29.9), and obese ( $\geq 30)$. At baseline, waist circumference (in inches) was measured at the level of maximum indentation over the abdomen. Based on the sex-specific American Heart Association cutoff points [40], waist circumference was categorized into small ( $\leq 35$ inches for females and $\leq 40$ inches for males) and large (>35 inches for females and $>40$ inches for males).

Other Covariates. At baseline, participants reported their country of birth (nativity) which was coded as US-born or Mexican-born, the years of education they have completed, marital status (married vs. other) and their past-month household income which was split at the median and classified as low (income $<1,500$ USD) or high (income $\geq 1,500$ USD). At baseline, glucose $(\mathrm{mg} / \mathrm{dl})$ and insulin levels were measured from fasting blood and systolic and diastolic blood pressure measurements were taken. The homeostatic model assessment for insulin resistance (HOMA-IR) was calculated as the product of fasting serum glucose $\times$ fasting serum insulin divided by 405 [41]. Diabetes was ascertained as a self-report of a physician diagnosis, use of diabetes medication, or a fasting glucose level $\geq 126 \mathrm{mg} / \mathrm{dl}$ [42]. Hypertension was ascertained as a report of a physician diagnosis, use of hypertension medication, a systolic blood pressure $>140 \mathrm{~mm} \mathrm{Hg}$ or a diastolic blood pressure $>90 \mathrm{~mm} \mathrm{Hg}$ [43]. Cardiovascular disease at baseline was ascertained by report of a physician diagnosis of vari- 
Fig. 1. Multivariable-adjusted associations of log Leptin (25th and 75th percentiles) with change in cognitive function among females from linear mixed effects models, stratified by waist circumference, SALSA, 1998-2008 (based on table 2). a Associations of log leptin percentiles with log 3MSE errors over time within females with a small waist circumference ( $\beta$-leptin by age interaction: $p=0.01$ ). b Associations of log leptin percentiles with log 3MSE errors over time within females with a large waist circumference ( $\beta$-leptin by age interaction: $p=0.36)$. c Associations of log leptin percentiles with change in SEVLT score over time among females with a small waist circumference ( $\beta$-leptin by age interaction: $p<0.01)$. d Associations of log percentiles with change in SEVLT score over time among females with a large waist circumference ( $\beta$-leptin by age interaction: $\mathrm{p}=0.52)$. 25th percentile of leptin $=2.7 \mathrm{ng} / \mathrm{ml}$ and 75 th percentile of leptin $=3.6 \mathrm{ng} / \mathrm{ml}$. Small waist $\leq 35$ inches and large waist $>35$ inches.

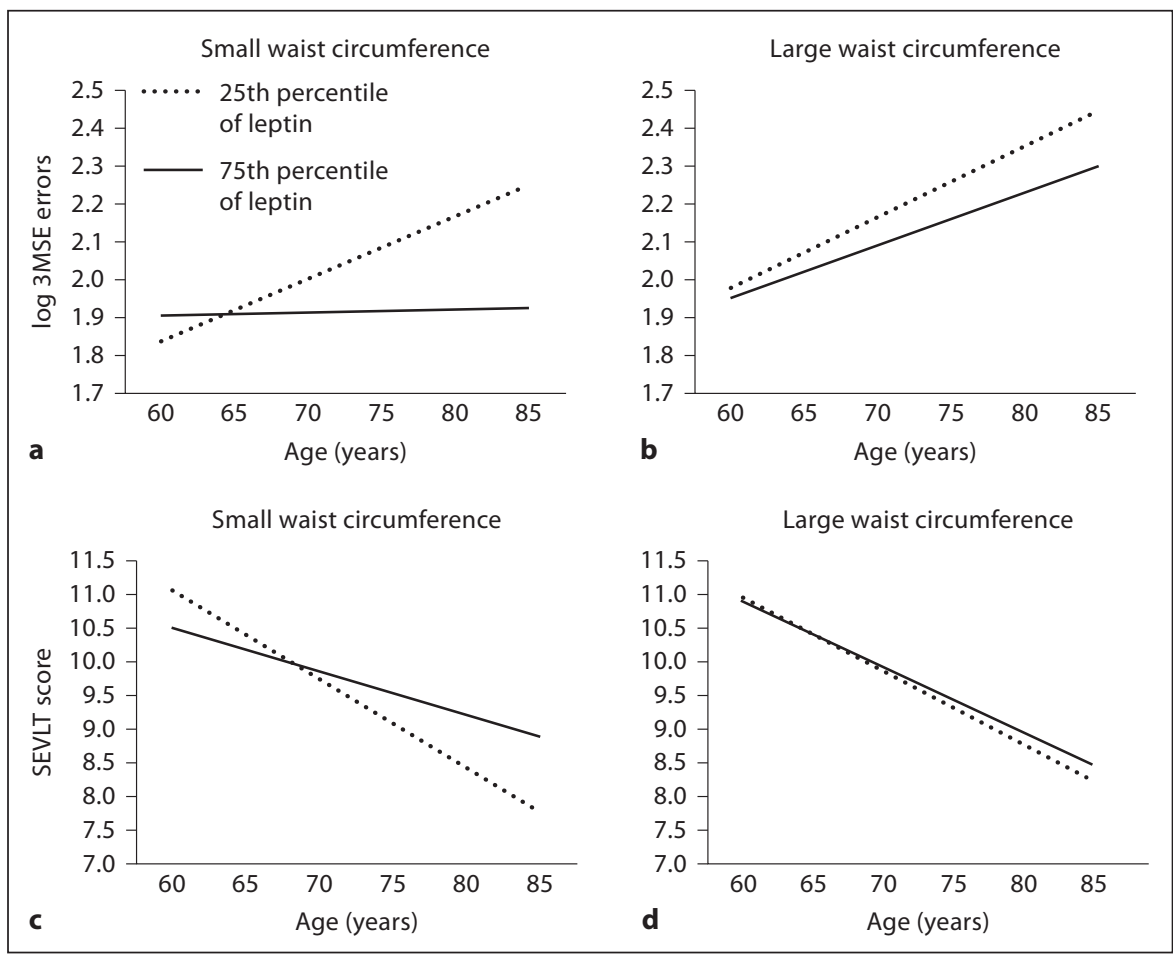

ous cardiovascular events such as myocardial infarction and stroke. Depressive symptoms were assessed using the 20-item version of the Center for Epidemiologic Studies Depression Scale (range 0-60) [44]. Smoking status (ever/never) and alcohol consumption (never, $<2$ drinks/week, $\geq 2$ drinks/week) were also reported during baseline interviews.

\section{Statistical Analyses}

Based on a priori knowledge and previous literature about gender differences in mean leptin levels, all analyses were conducted separately for females and males. In descriptive analyses, we used analysis of variance and Pearson correlations to examine bivariate associations between leptin levels and independent variables. Hierarchical linear mixed models were used to estimate the associations between leptin and change in cognitive function over the 10 -year period $[45,46]$ and to model change over time with unbalanced correlated data. The data structure for this analysis included two levels, namely, baseline and 6 follow-up time points (level 1) nested within 1,487 individuals (level 2). Accordingly, at level 1, we modeled the cognitive scores (logarithms of 3MSE errors or SEVLT scores) as a function of time. Time was operationalized as age at time of cognitive measurement instead of calendar time, primarily because leptin and cognition change as a function of age. Age was grand-mean-centered for each gender separately (70.16 years of age for females and 69.91 years of age for males). This analysis included regressions in which baseline cognitive function (i.e. intercept) and linear rate of cognitive change (i.e. slope) were specified as random effects. Leptin and 3MSE scores were log transformed (natural logarithm) to closely correspond to normal distributions as required by assumptions of the linear mixed model. We used log leptin as continuous in all analytic models and used the 25th and 75th percentiles when illustrating the predictions from the linear mixed models in figures 1 and 2. When interpreting the results with log 3MSE errors as the outcomes (including results from fig. 1 and 2), we used the exponent of the log of the $\beta$ coefficients to obtain the rates of change in the number of errors on the 3MSE.

Three-way interactions between leptin, waist circumference and age were tested to evaluate whether the relationship between leptin and cognitive decline was modified by central obesity. For purposes of clarity of presentation, we stratified all models by waist circumference. We first fit a model with leptin, age, and a leptin by age interaction to account for the leptin-associated cognitive decline (model 1). Second, important covariates were added in a fully adjusted model 2 . Covariates added at the multivariate level were chosen based on the literature and their bivariate associations with both leptin and cognitive function. We present estimates of regressions ( $\beta$ coefficients), their standard errors and associated two-sided $p$ values. The regression coefficients $(\beta)$ measure the association of changes in predictors within subjects with change in the outcomes. All statistical analyses were performed using SAS v. 9.2 [47].

\section{Results}

Table 1 shows baseline characteristics of the study population and their bivariate associations with leptin 
Fig. 2. Multivariable-adjusted associations of log Leptin (25th and 75th percentiles) with change in cognitive function among males from linear mixed effects models, stratified by waist circumference, SALSA, 1998-2008 (based on table 3). a Associations of log leptin percentiles with $\log 3 \mathrm{MSE}$ errors over time within males with a small waist circumference ( $\beta$-leptin by age interaction: $p=0.02)$. $\mathbf{b}$ Associations of log leptin percentiles with log 3MSE errors over time within males with a large waist circumference $(\beta$-leptin by age interaction: $p=0.28)$. $c$ Associations of $\log$ leptin percentiles with change in SEVLT score over time among males with small waist circumference ( $\beta$-leptin by age interaction: $\mathrm{p}=0.01)$. $\mathbf{d}$ Associations of $\log$ percentiles with change in SEVLT score over time among males with large waist circumference ( $\beta$-leptin by age interaction: $\mathrm{p}=0.18)$. 25th percentile of leptin $=$ $1.6 \mathrm{ng} / \mathrm{ml}$ and 75 th percentile of leptin = $2.5 \mathrm{ng} / \mathrm{ml}$. Small waist $\leq 40$ inches and large waist $>40$ inches.

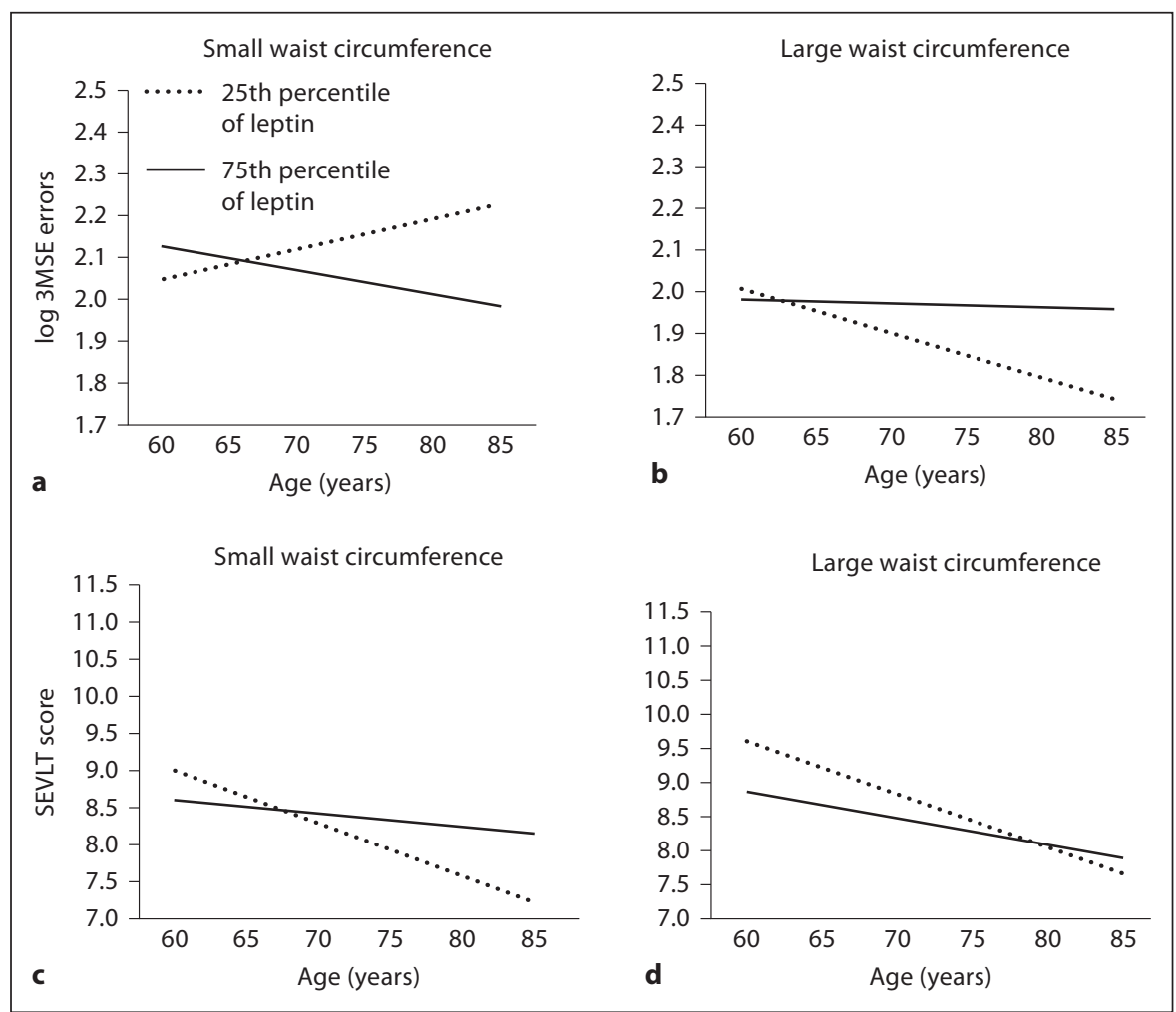

$(\log )$, by gender. Mean leptin levels were significantly higher $(\mathrm{p}<0.001)$ in females (mean $=3.1 \mathrm{ng} / \mathrm{ml}, \mathrm{SD}=$ 0.7 ) than in males (mean $=2.0 \mathrm{ng} / \mathrm{ml}, \mathrm{SD}=0.7)$. Among females, older age and being Mexican-born were associated with lower mean leptin. Having a higher BMI, a large waist circumference, higher HOMA-IR, type 2 diabetes and hypertension were associated with higher mean leptin among females. Among males, being USborn, having higher education, higher income, being married, and never smoking were associated with higher mean leptin. Also among males, a higher BMI, a large waist circumference, higher HOMA-IR, type 2 diabetes, hypertension, and cardiovascular disease were associated with higher mean leptin.

In an overall non-stratified model with a main effect for each of leptin and waist circumference in females, the $p$ value for the 3 -way interaction (leptin $\times$ waist circumference $\times$ age) was 0.09 with $3 \mathrm{MSE}$ as the outcome and the $p$ value was 0.02 with SEVLT as the outcome. For ease of interpretation, table 2 presents the results of linear mixed effects models of the associations between leptin (log) and change in cognitive function among females stratified by waist circumference. Within females with a small waist circumference ( $\leq 35$ inches), higher leptin was associated with slower rates of cognitive decline on the 3MSE and the SEVLT, after accounting for nativity, hypertension, HOMA-IR and type 2 diabetes (models 2 ). For example, higher leptin, a difference equivalent to the interquartile range, was associated with 2.0 fewer $3 \mathrm{MSE}$ points in cognitive decline over 10 years (equivalent to $35 \%$ less 3MSE errors) and 1.0 SEVLT point less in cognitive decline over 10 years (equivalent to $22 \%$ less decrease in SEVLT score). Within females with a large waist circumference ( $>35$ inches), higher leptin was not significantly associated with cognitive decline on the 3MSE or SEVLT, after accounting for nativity, hypertension, HOMA-IR and type 2 diabetes (models 2).

In an overall non-stratified model with a main effect for each of leptin and waist circumference in males, the $p$ value for the 3 -way interaction (leptin $\times$ waist circumference $\times$ age) was 0.02 with $3 \mathrm{MSE}$ as the outcome and the p value was 0.9 with SEVLT as the outcome. For ease of interpretation, table 3 presents the results of linear mixed effects models of the associations between leptin (log) and change in cognitive function among males stratified by waist circumference. Within males with a small waist circumference ( $\leq 40$ inches), higher leptin was associated with slower cognitive decline on the 3MSE and the 
Table 1. Sample characteristics and their bivariate associations with leptin (log), by gender, SALSA, 1998-2008

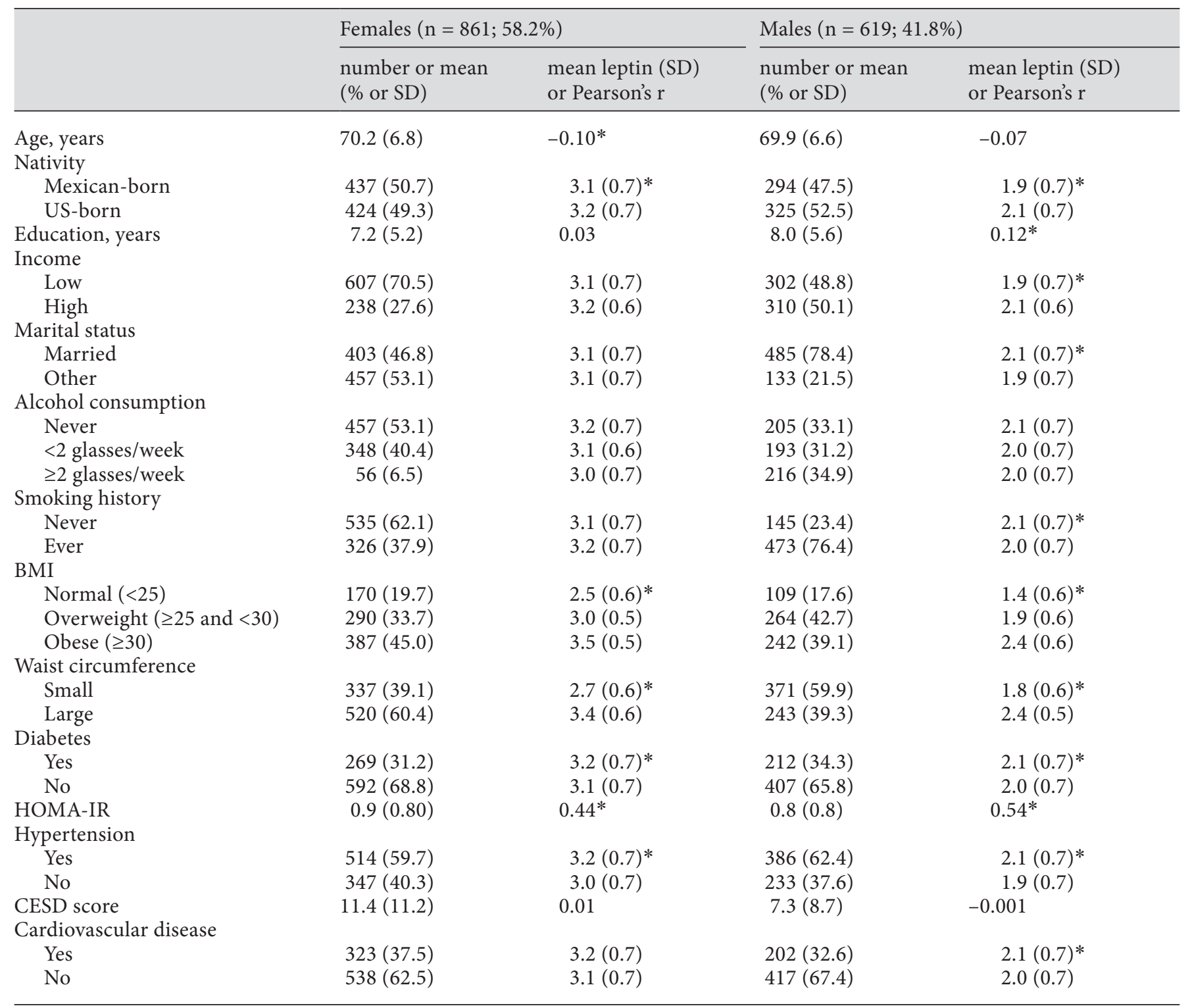

CESD $=$ Center for Epidemiologic Studies Depression Scale. Small waist circumference: $\leq 35$ inches for females and $\leq 40$ inches for males; large waist circumference: $>35$ inches for females and $>40$ inches for males. $* \mathrm{p}<0.05$.

SEVLT, after accounting for nativity, education, income, HOMA-IR and type 2 diabetes (models 2). For example, higher leptin, a difference equivalent to the interquartile range, was associated with 1.3 fewer $3 \mathrm{MSE}$ points in cognitive decline over 10 years (equivalent to $44 \%$ less $3 \mathrm{MSE}$ errors) and 0.5 SEVLT points less in cognitive decline over 10 years (equivalent to $30 \%$ less decrease in SEVLT score). Within males with a large waist circumference (>40 inches), higher leptin was not significantly associat- ed with rates of cognitive decline on the 3MSE or SEVLT, from fully adjusted models (models 2).

The multivariable-adjusted associations between leptin (25th and 75th percentiles) and changes in cognitive function over time (as age) among females are further illustrated in figure 1 (based on models 2 of table 2 ). For each cognitive outcome (log 3MSE errors and SEVLT), there are two panels pertaining to the association between leptin and cognitive decline within waist 
Table 2. Multivariable-adjusted associations of leptin with change in cognitive function among females from linear mixed effects models, stratified by waist circumference, SALSA, 1998-2008

\begin{tabular}{|c|c|c|c|c|}
\hline & \multicolumn{4}{|c|}{ Waist circumference } \\
\hline & $\begin{array}{l}\text { model } 1 \\
\beta(\mathrm{SE})\end{array}$ & $\begin{array}{l}\text { model } 2 \\
\beta(\mathrm{SE})\end{array}$ & $\begin{array}{l}\text { model } 1 \\
\beta(\mathrm{SE})\end{array}$ & $\begin{array}{l}\text { model } 2 \\
\beta(S E)\end{array}$ \\
\hline \multicolumn{5}{|c|}{ Outcome: $\log 3 M S E$ errors } \\
\hline Intercept & $2.44(0.18)^{*}$ & $2.22(0.19)^{*}$ & $2.84(0.20)^{*}$ & $2.39(0.20)^{*}$ \\
\hline log leptin & $-0.11(0.06)$ & $-0.10(0.07)$ & $-0.15(0.06)^{*}$ & $-0.09(0.06)$ \\
\hline log leptin $\times$ age & $-0.02(0.01)^{*}$ & $-0.02(0.01)^{*}$ & $-0.003(0.01)$ & $-0.01(0.01)$ \\
\hline AIC & $3,400.7$ & $3,341.5$ & $4,887.6$ & $4,770.8$ \\
\hline \multicolumn{5}{|l|}{ Outcome: SEVLT } \\
\hline Intercept & $9.06(0.59)^{*}$ & $9.58(0.64)^{*}$ & $8.54(0.56)^{*}$ & $9.77(0.59)^{*}$ \\
\hline Age & $-0.35(0.07)^{*}$ & $-0.34(0.07)^{*}$ & $-0.12(0.07)$ & $-0.14(0.07)^{*}$ \\
\hline
\end{tabular}

$* \mathrm{p}<0.05$. Model 1 is unadjusted; model 2 additionally adjusts for nativity, hypertension, type 2 diabetes and HOMA-IR. AIC $=$ Akaike Information Criterion.

Table 3. Multivariable-adjusted associations of leptin with change in cognitive function among males from linear mixed effects models, stratified by waist circumference, SALSA, 1998-2008

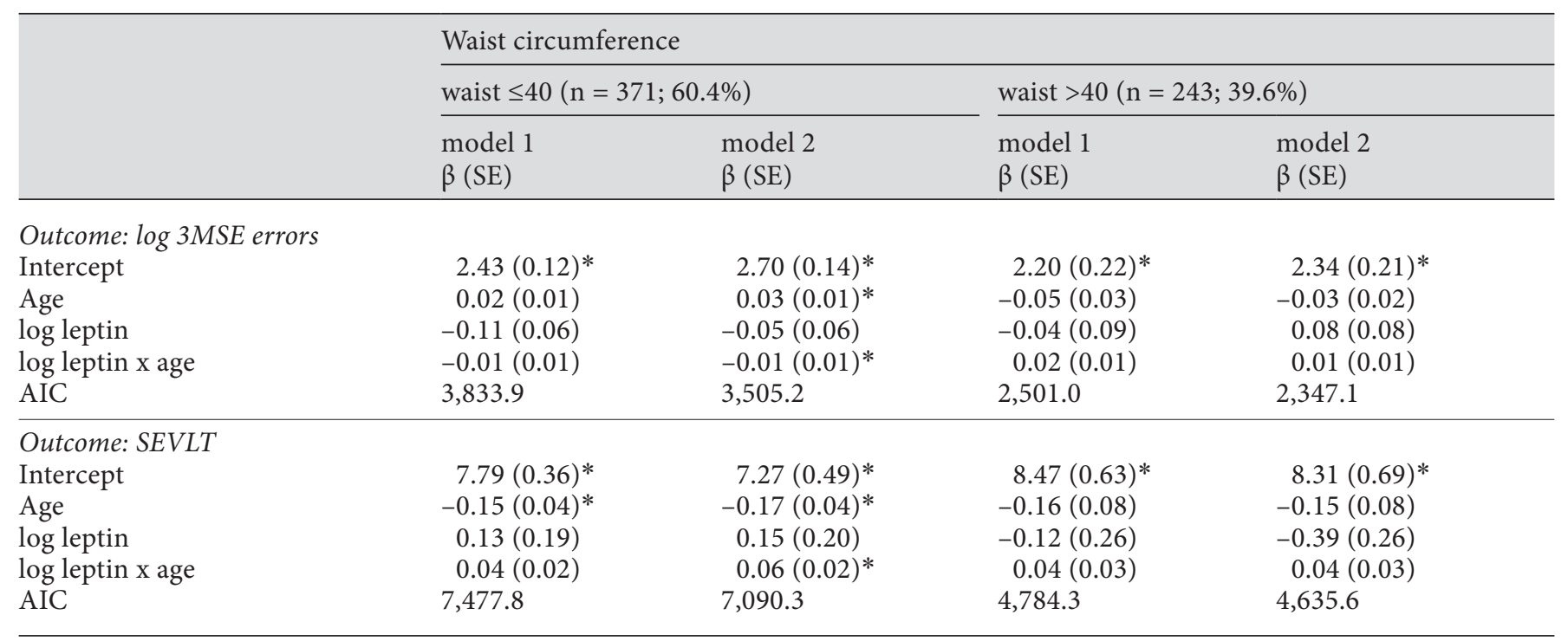

* $\mathrm{p}<0.05$. Model 1 is unadjusted; model 2 additionally adjusts for nativity, education, income, type 2 diabetes, and HOMA-IR. AIC $=$ Akaike Information Criterion. 
circumference categories (small waist and large waist). For the 3MSE outcome, within females with a small waist circumference (fig. 1a), the slope of age-related increase in 3MSE errors was more rapid for those with low leptin (at 25th percentile of $2.7 \mathrm{ng} / \mathrm{ml}$ ) compared to those with high leptin (at 75 th percentile of $3.6 \mathrm{ng} / \mathrm{ml}$ ) with a crossover at age 65 in favor of high leptin. For example, at age 85 , those with low leptin had 10 errors on the $3 \mathrm{MSE}$ compared to 7 errors for those with high leptin. Within females with a large waist circumference (fig. 1b), there was no association between increased leptin (higher percentile) and change in 3MSE errors over time ( $\beta$ leptin by age interaction: $\mathrm{p}=0.36$ ). As for the SEVLT outcome, within females with a small waist circumference (fig. 1c), the slope of age-related decrease in SEVLT total score was more rapid among those with low leptin than those with high leptin with a cross-over around age 70 in favor of high leptin. Again at age 85, those with low leptin had a total SEVLT score of 7.8 compared to a score of 9.0 for those with high leptin. Within females with a large waist circumference (fig. 1d), the age-related slope of change in SEVLT score was not different by leptin level ( $\beta$ leptin by age interaction: $\mathrm{p}=0.52$ ).

The multivariable-adjusted associations between leptin (25th and 75th percentiles) and changes in cognitive function over time (as age) among males are further illustrated in figure 2 (based on models 2 of table 3). For each cognitive outcome (log 3MSE errors and SEVLT), there are two panels pertaining to the association between leptin and cognitive decline within waist circumference categories (small waist and large waist). For the 3MSE outcome, within males with a small waist circumference (fig. 2a), the slope of age-related increase in 3MSE errors was more rapid among those with low leptin (at 25 th percentile of $1.6 \mathrm{ng} / \mathrm{ml}$ ) than those with high leptin (at 75th percentile of $2.5 \mathrm{ng} / \mathrm{ml}$ ) with a cross-over at age 65 in favor of high leptin. For example, at age 85, those with low leptin had 9.0 errors on the 3MSE compared to 7.0 errors for those with high leptin. Within males with a large waist circumference (fig. $2 b$ ), higher leptin was not in favor of less 3MSE errors ( $\beta$ leptin by age interaction: $\mathrm{p}=0.28$ ). As for the SEVLT outcome, within males with a small waist circumference (fig. 2c), the slope of age-related decrease in SEVLT total score was more rapid among those with low leptin than those with high leptin with a cross-over around age 68 in favor of high leptin. For example at age 85 , those with low leptin had a total SEVLT score of 7.2 compared to a score of 8.2 for those with high leptin. Within males with a large waist circumference (fig. 2d), the age-related slope of change in SEVLT score was not significantly different by leptin level ( $\beta$ leptin by age interaction: $\mathrm{p}=0.18$ ).

\section{Discussion}

In our cohort of older Mexican Americans, higher baseline leptin was associated with better cognitive function over time for females and males without central obesity as measured by waist circumference. For those with a large waist circumference, there was no association between leptin and change in cognitive function.

Our findings are in line with previous studies on rodent models suggesting mechanisms through which leptin influences brain structure and function. First, through its influence on the synaptic plasticity of the hippocampus, leptin improved memory and learning functions [16]. For example, a dysfunction in leptin receptors has been associated with impaired performance on spatial memory tasks [27]. Furthermore, providing leptin to the hippocampus of leptin-deficient or resistant rats was associated with enhanced memory and learning processes [15]. Second, leptin is thought to enhance N-methyl-Daspartate receptor function which modulates short-term potentiation into long-term potentiation in the hippocampus $[16,26]$. Third, leptin is thought to influence apolipoprotein-E-mediated uptake of $\beta$-amyloid, a major hallmark of $\mathrm{AD}$ [18].

A few population-based studies have evaluated the effects of leptin on cognitive function. Cross-sectional results among patients from two teaching hospitals in Dublin have shown that those with AD have lower levels of serum leptin than patients without AD diagnosis [29]. There were three longitudinal studies that examined the link between leptin and cognitive decline or risk of dementia. The first study was among black and white older adult participants of the Health, Aging and Body Composition study (Health $\mathrm{ABC}$ ) and suggested an inverse relation between baseline serum leptin level and rate of cognitive decline over a much shorter period (4 years) of follow-up [28]. The second study was among participants of the Framingham study and found that higher leptin was associated with lower hazards of dementia and $\mathrm{AD}$ [24]. The third study was among participants of the Study of Osteoporotic Fractures, which found that higher leptin was associated with lower odds of dementia and mild cognitive impairment [25].

Results from our analyses showed that the association between leptin and change in cognitive function differed by waist circumference, a measure of central abdominal 
obesity. Our results differ from the findings of the Health $\mathrm{ABC}$ study in which the association between leptin and cognitive decline was adjusted for BMI or percent body fat [28]. The authors of that study did not report whether or not an interaction of leptin with BMI or percent body fat was found. Our results are more consistent with those of the Framingham study and the Study of Osteoporotic Fractures in which higher leptin was associated with lower hazards of dementia/mild cognitive impairment and $\mathrm{AD}$ among subjects with a low BMI $[24,25]$ and low waist-to-hip ratio [24] but not among obese subjects.

General or abdominal obesity are risk factors for cognitive impairment and may operate through various underlying pathways [48-50]. For example, obese subjects may be more likely to develop hyperleptinemia [20], which may result in compromised leptin transport across the blood-brain barrier as well as reduced leptin signaling [21-23] which may ultimately interfere with leptin action on the brain. Furthermore, obesity-related inflammation is suggested to interfere with the action of leptin on the brain further inducing leptin resistance [48]. These mechanisms may possibly explain why participants with central obesity, potentially due to increased leptin resistance in the brain [51], may not benefit from the protective effect of higher leptin against cognitive impairment. In our study, BMI did not modify the relationship between leptin and cognitive decline (data not shown) which may be attributed to the fact that BMI is an overall measure of obesity and body size and may not be as informative as waist circumference with regard to body fat distribution. Waist circumference is a better measure of abdominal adiposity than BMI and is thus closely related to leptin production and secretion [52]. Given that the 3-way interaction between leptin, waist circumference and age was statistically significant for females and males, it is possible to assume that this interaction was superadditive such that low leptin level and high central obesity interact resulting in a greater rate of decline. Finally, while insulin resistance [7-9] and type 2 diabetes [10-13] may constitute important pathways for the link between central obesity, leptin, and cognitive decline, adjusting for type 2 diabetes and HOMA-IR at the multivariable level produced similar results.

Our data also indicated that the patterns of effect of higher leptin on 3MSE among subjects with a large waist circumference differed by gender. For females with a large waist circumference, having leptin at the 25th or 75th percentiles was associated with an increase in 3MSE errors over time. For males with a large waist circumference, there was a decrease in the number of 3MSE errors over

Central Obesity, Leptin and Cognitive

Decline time for those with the 25th percentile of leptin and almost no change in errors for those with the 75th percentile (though not statistically significant, i.e. $\beta$-leptin by age interaction: $p>0.05$ ). Prior studies have reported gender interactions between increasing adiposity measures and cognitive outcomes such that females and males showed different trends of associations [53-56]. Furthermore, recent studies have shown gender differences in the effect of other adipose-tissue-derived hormones, such as adiponectin, on cognitive impairment and dementia $[57,58]$. These studies suggested that the threshold at which these adipose-tissue-derived hormones played a role in the risk of dementia may be different for females and males [58]. However, no studies have previously explored the interaction of leptin, central obesity and cognitive decline by gender, particularly for Mexican Americans. Future studies need to carefully examine these relationships.

In this study, although we present the results of leptin only, we did explore the associations of adiponectin and the leptin to adiponectin ratio with cognitive decline (data not shown). Adiponectin was not associated with cognitive decline in our study cohort. The association of leptin to adiponectin ratio with cognitive decline was similar to that of leptin, possibly due to the fact that adiponectin played no role in this relationship. We also performed sensitivity analyses to examine whether HOMA-IR and type 2 diabetes modified the associations between leptin and cognitive outcomes while adjusting for waist circumference. In females, the association of leptin with cognitive decline on the 3MSE was not modified by HOMA-IR ( $\mathrm{p}$ interaction $=0.7)$ nor type 2 diabetes ( $\mathrm{p}$ interaction $=0.7$ ); similarly for the association of leptin with cognitive decline on the SEVLT ( $\mathrm{p}=0.2$ with HOMA-IR and $\mathrm{p}=0.9$ with type 2 diabetes). In males, the association of leptin with cognitive decline on the 3MSE was also not modified by HOMA-IR ( $\mathrm{p}$ interaction $=0.5$ ) nor type 2 diabetes $(p$ interaction $=0.9)$; similarly for the association of leptin with cognitive decline on the SEVLT ( $p=$ 0.7 with HOMA-IR and $\mathrm{p}=0.05$ with type 2 diabetes). Given that these interactions were not significant, this corroborates our findings that the effect modification by waist circumference is rather more specific to adiposity differences than to insulin resistance or type 2 diabetes.

Our study has some limitations that are worth noting. First, leptin levels may be subject to diurnal variation [59]; however, this does not bias our results since leptin was measured at the same time (fasting during the morning) for all our study participants. Second, while we adjusted for potential confounders separately for females and males, the possibility of residual confounding cannot 
be completely ruled out. Finally, given the longitudinal nature of the study, attrition due to death or loss to follow-up may have resulted in bias of the relationships of interest since those who suffered from attrition had lower baseline cognitive function and lower mean leptin level. In spite of these limitations, to our knowledge, our study is the first prospective study to examine the relationship of leptin, central obesity and cognitive decline among older Mexican Americans. In light of the scarcity of cognitive data among Mexican Americans, our results take advantage of a unique prospectively followed cohort with repeated measures of cognitive function and clinical and biologic data. Our results thus constitute an important addition to the literature on metabolic risk factors and change in cognitive function among aging ethnic minority groups.

Our results provide evidence that central obesity interacts with leptin in shaping cognitive function. This is the first population-based study to examine the link between leptin, central obesity, and cognitive decline among Mexican Americans. Our findings may have important implications for a fast-growing minority group with increasing rates of obesity and type 2 diabetes and thus provide valuable information about the influence of metabolic risk factors on cognitive function. Further studies are needed to confirm our results.

\section{Acknowledgements}

This work is supported by grants from the National Institute on Aging (AG12975, AG033751) and National Institute of Diabetes and Digestive and Kidney Diseases (DK60753). Dr. Zeki Al Hazzouri is supported by the American Heart Association/American Stroke Association/American Brain Foundation Lawrence M. Brass, M.D., Stroke Research Postdoctoral Fellowship.

\section{References}

1 Dewey ME, Saz P: Dementia, cognitive impairment and mortality in persons aged 65 and over living in the community: a systematic review of the literature. Int J Geriatr Psychiatry 2001;16:751-761.

2 Hendrie HC: Epidemiology of dementia and Alzheimer's disease. Am J Geriatr Psychiatry 1998;6:S3-S18.

-3 Laitala VS, Kaprio J, Koskenvuo M, Raiha I, Rinne JO, Silventoinen K: Association and causal relationship of midlife obesity and related metabolic disorders with old age cognition. Curr Alzheimer Res 2011;8:699-706.

-4 Anstey KJ, Cherbuin N, Budge M, Young J: Body mass index in midlife and late-life as a risk factor for dementia: a meta-analysis of prospective studies. Obes Rev 2011;12: e426-e437.

5 Whitmer RA, Gunderson EP, Barrett-Connor E, Quesenberry CP Jr, Yaffe K: Obesity in middle age and future risk of dementia: a 27 year longitudinal population based study. BMJ 2005;330:1360.

6 Whitmer RA, Gustafson DR, Barrett-Connor E, Haan MN, Gunderson EP, Yaffe K: Central obesity and increased risk of dementia more than three decades later. Neurology 2008;71:1057-1064.

7 Craft S: Insulin resistance syndrome and Alzheimer's disease: age- and obesity-related effects on memory, amyloid, and inflammation. Neurobiol Aging 2005;26(suppl 1):65-69.

$\$ 8$ Craft S: Insulin resistance and Alzheimer's disease pathogenesis: potential mechanisms and implications for treatment. Curr Alzheimer Res 2007;4:147-152.
-9 Gasparini L, Gouras GK, Wang R, Gross RS, Beal MF, Greengard P, Xu H: Stimulation of beta-amyloid precursor protein trafficking by insulin reduces intraneuronal beta-amyloid and requires mitogen-activated protein kinase signaling. J Neurosci 2001;21: 2561-2570.

10 Umpierrez GE, Gonzalez A, Umpierrez D, Pimentel D: Diabetes mellitus in the Hispanic/Latino population: an increasing health care challenge in the United States. Am J Med Sci 2007;334:274-282.

11 Carter JS, Pugh JA, Monterrosa A: Non-insulin-dependent diabetes mellitus in minorities in the United States. Ann Intern Med 1996;125:221-232.

-12 Luchsinger JA, Tang MX, Stern Y, Shea S, Mayeux R: Diabetes mellitus and risk of Alzheimer's disease and dementia with stroke in a multiethnic cohort. Am J Epidemiol 2001; 154:635-641.

$\checkmark 13$ Egede LE, Dagogo-Jack S: Epidemiology of type 2 diabetes: focus on ethnic minorities. Med Clin North Am 2005;89:949-975, viii.

$\checkmark 14$ Elmquist JK, Maratos-Flier E, Saper CB, Flier JS: Unraveling the central nervous system pathways underlying responses to leptin. Nat Neurosci 1998;1:445-450.

15 Farr SA, Banks WA, Morley JE: Effects of leptin on memory processing. Peptides 2006; 27:1420-1425.

16 HarveyJ,Solovyova N, Irving A:Leptin andits role in hippocampal synaptic plasticity. Prog Lipid Res 2006;45:369-378.
17 Skeberdis VA, Lan J, Zheng X, Zukin RS, Bennett MV: Insulin promotes rapid delivery of N-methyl-D-aspartate receptors to the cell surface by exocytosis. Proc Natl Acad Sci USA 2001;98:3561-3566.

18 Fewlass DC, Noboa K, Pi-Sunyer FX, Johnston JM, Yan SD, Tezapsidis N: Obesity-related leptin regulates Alzheimer's Abeta. FASEB J 2004;18:1870-1878.

19 Caro JF, Kolaczynski JW, Nyce MR, Ohannesian JP, Opentanova I, Goldman WH, Lynn RB, Zhang PL, Sinha MK, Considine RV: Decreased cerebrospinal-fluid/serum leptin ratio in obesity: a possible mechanism for leptin resistance. Lancet 1996;348: 159-161.

20 Considine RV, Sinha MK, Heiman ML, Kriauciunas A, Stephens TW, Nyce MR, Ohannesian JP, Marco CC, McKee LJ, Bauer TL, et al: Serum immunoreactive-leptin concentrations in normal-weight and obese humans. N Engl J Med 1996;334:292-295.

21 ArchJR:Central regulation of energybalance: inputs, outputs and leptin resistance. Proc Nutr Soc 2005;64:39-46.

$\checkmark 22$ Banks WA, Coon AB, Robinson SM, Moinuddin A, Shultz JM, Nakaoke R, Morley JE: Triglycerides induce leptin resistance at the blood-brain barrier. Diabetes 2004;53: 1253-1260.

23 Steinberg GR, McAinch AJ, Chen MB, O'Brien PE, Dixon JB, Cameron-Smith D, Kemp BE: The suppressor of cytokine signaling 3 inhibits leptin activation of ampkinase in cultured skeletal muscle of obese humans. J Clin Endocrinol Metabol 2006;91: 3592-3597. 
- 24 Lieb W, Beiser AS, Vasan RS, Tan ZS, Au R, Harris TB, Roubenoff R, Auerbach S, DeCarli C, Wolf PA, Seshadri S: Association of plasma leptin levels with incident Alzheimer disease and MRI measures of brain aging. JAMA 2009;302:2565-2572.

25 Zeki Al Hazzouri A, Stone K, Haan MN, Yaffe K: Leptin, mild cognitive impairment (MCI) and dementia among elderly women. J Gerontol A Biol Sci Med Sci, in press.

26 Shanley LJ, Irving AJ, Harvey J: Leptin enhances NMDA receptor function and modulates hippocampal synaptic plasticity. J Neurosci 2001;21:RC186.

-27 Li XL, Aou S, Oomura Y, Hori N, Fukunaga $\mathrm{K}$, Hori T: Impairment of long-term potentiation and spatial memory in leptin receptordeficient rodents. Neuroscience 2002;113: 607-615.

-28 Holden KF, Lindquist K, Tylavsky FA, Rosano C, Harris TB, Yaffe K: Serum leptin level and cognition in the elderly: findings from the health ABC study. Neurobiol Aging 2009; 30:1483-1489.

-29 Power DA, Noel J, Collins R, O’Neill D: Circulating leptin levels and weight loss in Alzheimer's disease patients. Dement Geriatr Cogn Disord 2001;12:167-170.

-30 Cossrow N, Falkner B: Race/ethnic issues in obesity and obesity-related comorbidities. J Clin Endocrinol Metabol 2004;89: 2590-2594.

- 31 Nicklas BJ, Toth MJ, Goldberg AP, Poehlman ET: Racial differences in plasma leptin concentrations in obese postmenopausal women. J Clin Endocrinol Metabol 1997;82: 315-317.

- 32 Perry HM 3rd, MorleyJE, Horowitz M, Kaiser FE, Miller DK, Wittert G: Body composition and age in African-American and Caucasian women: relationship to plasma leptin levels. Metabolism 1997;46:1399-1405.

- 33 Ruhl CE, Everhart JE: Leptin concentrations in the United States: relations with demographic and anthropometric measures. Am J Clin Nutr 2001;74:295-301.

34 Wei M, Stern MP, Haffner SM: Serum leptin levels in Mexican Americans and non-Hispanic whites: association with body mass index and cigarette smoking. Ann Epidemiol 1997;7:81-86.

-35 Haan MN, Mungas DM, Gonzalez HM, Ortiz TA, Acharya A, Jagust WJ: Prevalence of dementia in older Latinos: the influence of type 2 diabetes mellitus, stroke and genetic factors. J Am Geriatr Soc 2003;51:169-177.

36 Teng EL, Chui HC: The Modified Mini-MentalState (3MS) examination. JClin Psychiatry 1987;48:314-318.
37 Tombaugh TN: Test-retest reliable coefficients and 5-year change scores for the MMSE and 3MS. Arch Clin Neuropsychol 2005;20: 485-503.

38 Gonzalez HM, Mungas D, Haan MN: A verbal learning and memory test for English- and Spanish-speaking older Mexican-American adults. Clin Neuropsychol 2002;16:439-451.

39 Gonzalez HM, Mungas D, Haan MN: A semantic verbal fluency test for English- and Spanish-speaking older Mexican-Americans. Arch Clin Neuropsychol 2005;20:199-208.

- 40 Poirier P, Giles TD, Bray GA, Hong Y, Stern JS, Pi-Sunyer FX, Eckel RH: Obesity and cardiovascular disease: pathophysiology, evaluation, and effect of weight loss: an update of the 1997 American Heart Association Scientific Statement on Obesity and Heart Disease from the Obesity Committee of the Council on Nutrition, Physical Activity, and Metabolism. Circulation 2006;113: 898-918.

41 Matthews DR, Hosker JP, Rudenski AS, Naylor BA, Treacher DF, Turner RC: Homeostasis model assessment: insulin resistance and beta-cell function from fasting plasma glucose and insulin concentrations in man. Diabetologia 1985;28:412-419.

42 The American Diabetes Association: Diagnosis and classification of diabetes mellitus. Diabetes Care 2006;29(Suppl 1):S43-S48.

43 Joint National Committee on Prevention, Detection, Evaluation, and Treatment of High Blood Pressure. The Sixth Report of the Joint National Committee on Prevention, Detection, Evaluation, and Treatment of High Blood Pressure (JNC VI). Arch Intern Med. 1997; 157:2413-2446.

44 Gonzalez HM, Haan MN, Hinton L: Acculturation and the prevalence of depression in older Mexican Americans: baseline results of the Sacramento Area Latino Study on aging. J Am Geriatr Soc 2001;49:948-953.

45 McCulloch CE, Searle SR, Neuhaus JM: Generalized, Linear and Mixed Models, ed 2. New York, Wiley, 2008.

46 Singer JD, Willett JB: Applied Longitudinal Data Analysis: Modeling Change and Event Occurrence. New York, Oxford University Press Inc, 2003.

47 SAS Institute. SAS Statistical Software, Release 9.2. Cary, SAS Institute, 2005.

48 Chen K, Li F, Li J, Cai H, Strom S, Bisello A, Kelley DE, Friedman-Einat M, Skibinski GA, McCrory MA, Szalai AJ, Zhao AZ: Induction of leptin resistance through direct interaction of C-reactive protein with leptin. Nat Med 2006;12:425-432.
49 Raji CA, Ho AJ, Parikshak NN, Becker JT, Lopez OL, Kuller LH, Hua X, Leow AD, Toga AW, Thompson PM: Brain structure and obesity. Hum Brain Mapp 2010;31:353-364.

50 Driscoll I, Beydoun MA, An Y, Davatzikos C, Ferrucci L, Zonderman AB, Resnick SM: Midlife obesity and trajectories of brain volume changes in older adults. Hum Brain Mapp, in press.

51 Myers MG, Cowley MA, Munzberg H: Mechanisms of leptin action and leptin resistance. Annu Rev Physiol 2008;70:537-556.

52 Considine RV, Premkumar A, Reynolds JC, Sebring NG, Ricks M, Sumner AE: Adiponectin and leptin in African Americans. Obesity 2008; 16:428-434.

53 Kanaya AM, Lindquist K, Harris TB, Launer L, Rosano C, Satterfield S, Yaffe K: Total and regional adiposity and cognitive change in older adults: the health, aging and body composition (ABC) study. Arch Neurol 2009;66: 329-335.

54 Beydoun MA, Lhotsky A, Wang Y, Dal Forno G, An Y, Metter EJ, Ferrucci L, O’Brien R, Zonderman AB: Association of adiposity status and changes in early to mid-adulthood with incidence of Alzheimer's disease. Am J Epidemiol 2008;168:1179-1189.

55 Hayden KM, Zandi PP, Lyketsos CG, Khachaturian AS, Bastian LA, Charoonruk G, Tschanz JT, Norton MC, Pieper CF, Munger RG, Breitner JC, Welsh-Bohmer KA: Vascular risk factors for incident Alzheimer disease and vascular dementia: the Cache County Study. Alzheimer Dis Assoc Disord 2006;20: 93-100.

56 Whitmer RA, Gunderson EP, Quesenberry CP Jr, Zhou J, Yaffe K: Body Mass Index in midlife and risk of Alzheimer disease and vascular dementia. Curr Alzheimer Res 2007;4: 103-109.

57 Kamogawa K, Kohara K, Tabara Y, Uetani E, Nagai T, Yamamoto M, Igase M, Miki T: Abdominal fat, adipose-derived hormones and mild cognitive impairment: The J-SHIPP study. Dement Geriatr Cogn Disord 2010;30: 432-439.

58 van Himbergen TM, Beiser AS, Ai M, Seshadri S, Otokozawa S, Au R, Thongtang N, Wolf PA, Schaefer EJ: Biomarkers for insulin resistance and inflammation and the risk for all-cause dementia and Alzheimer disease: results from the Framingham Heart Study. Arch Neurol 2012, E-pub ahead of print.

59 Licinio J, Mantzoros C, Negrao AB, Cizza G, Wong ML, Bongiorno PB, Chrousos GP, Karp B, Allen C, Flier JS, Gold PW: Human leptin levels are pulsatile and inversely related to pituitary-adrenal function. Nat Med 1997;3:575-579. 